\title{
Infecção por Ichthyophthirius multifiliis (Protozoa) em acari, Ancistrus sp. (Pisces: Teleostei), capturado em Belém, Estado do Pará
}

\section{Ichthyophthirius multifiliis (Protozoa) in acari, Ancistrus sp. (Pisces: Teleostei), captured in Belém, State of Pará}

\author{
Edilson Matos ${ }^{1}$, Sérgio Carmona de São Clemente², Carlos Azevedo ${ }^{3}$, Eulógio Carlos Queiroz de Carvalho, \\ Francisco Carlos de Lima²
}

\section{Resumo}

É reportado um caso de ictiofitiríase em acari (Ancistrus sp.), em Belém, Estado do Pará. O hospedeiro apresentava pontos brancos sobre a superfície corporal e nas brânquias. Ao exame histopatológico, as brânquias revelaram um processo congestivo vascular e hemorragia moderada, além de hiperplasia focal das lamelas secundárias com a conseqüente fusão das mesmas. Trofontes típicos do protozoário lchthyophthirius multifiliis foram observados entre os espaços interlamelares.

Palavras chave: Ichthyophthirius multifiliis; ictiofitiríase; acari; Ancistrus sp.

Ichthyophthirius multifiliis é um protozoário ciliado e, provavelmente, o parasito de peixes de mais ampla distribuição no mundo (Hoffman, 1970; Paperna, 1980) com capacidade para infectar qualquer espécie de água doce (Reichenbach-Klinke, 1980). No hospedeiro é facilmente observado na superfície corporal e nas brânquias sob a forma de pequenos pontos brancos (Roberts, 1978; Eiras, 1994) e pode provocar grande mortalidade nas infecções severas. É mais comumente encontrado em peixes de cultivo. A ictiofitiríase possui abundante literatura em países de intensa piscicultura. No Brasil, embora conhecida por aquaristas e pesquisadores da área, é raramente documentada.

O presente trabalho registra a primeira observação de ictiofitiríase em peixe acari (Ancistrus sp.) no Brasil. O espécime apresentava pequenos pontos brancos em sua superficie e nas brânquias. Após o sacrifício foi retirado um fragmento branquial, no qual procedeu-se a técnica usual para inclusão em parafina e coloração pela hematoxilina-eosina.

A amostra revelou, ao microscópio, sinais de comprometimento vascular e congestão moderados, além de discreta hemorragia e hiperplasia focal das lamelas secundárias com a conseqüente fusão das mesmas. Observou-se, ainda, que os pontos brancos eram formas parasitárias de I. multifiliis, com formato arredondado e macronúcleo central (Figs.1, 2).

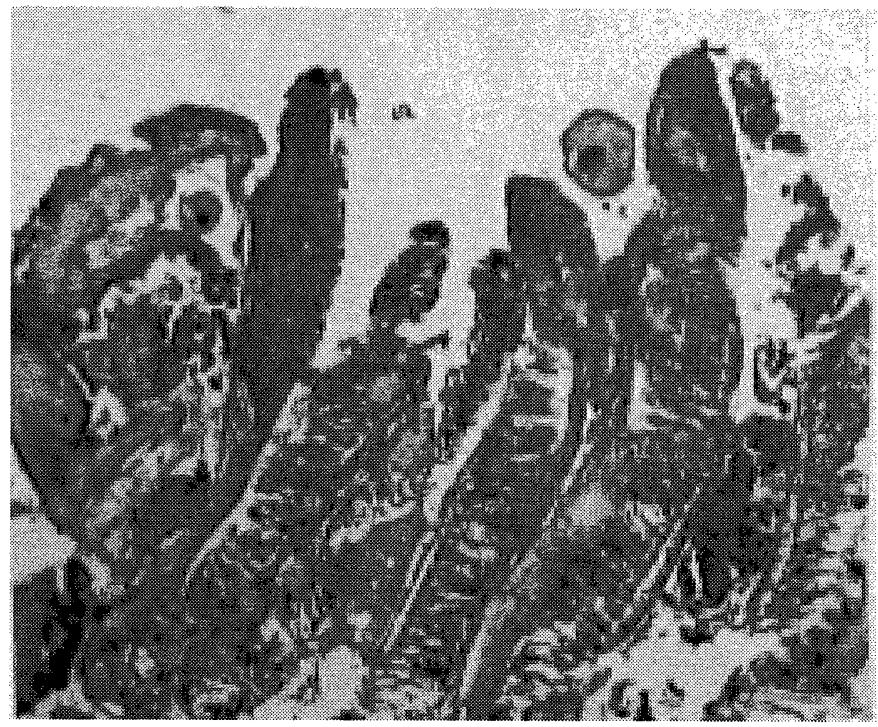

Figura 1 - Fotomicrografia de brânquia de acari (Ancistrus sp.) mostrando o aspecto geral da lesão hiperplásica e a presença de duas células parasitárias de Ichthyophthirius multifiliis. Aumento: objetiva 4X. Coloração: HE.

${ }^{1}$ Faculdade de Ciências Agrárias do Pará, Belém, PA, Brasil

2Departamento de Tecnologia de Alimentos, Faculdade de Veterinária, Universidade Federal Fluminense, UFF, Rua Vital Brasil Filho 64, 24230 340 Niterói, RJ, Brasil

3Universidade do Porto, Porto, Portugal

${ }^{4}$ Departamento de Patologia, Faculdade de Medicina, UFF 


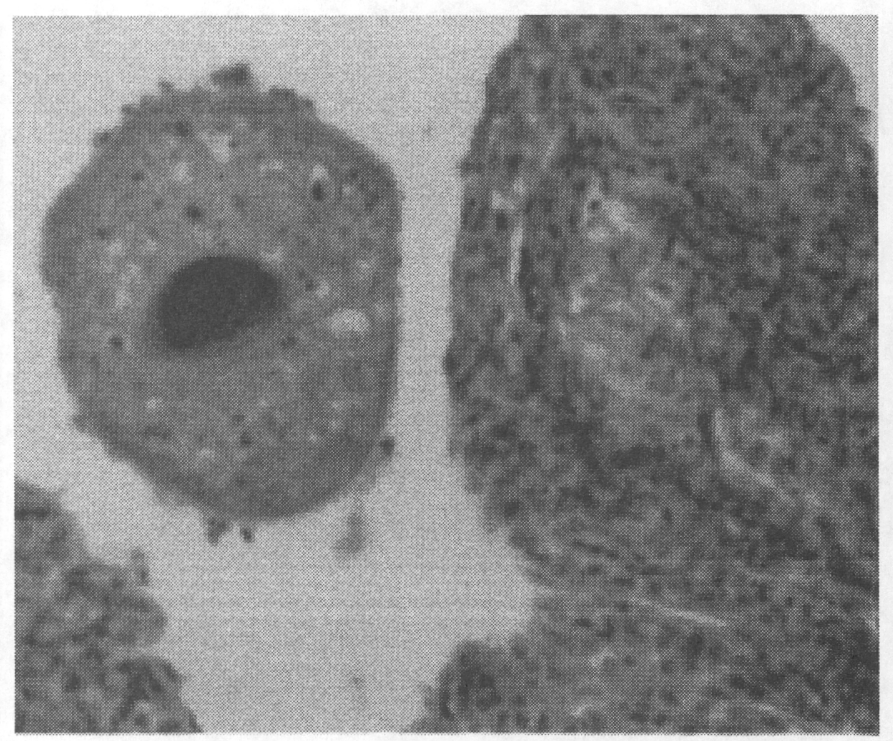

Figura 2 - Fotomicrografia de brânquia de acari (Ancistrus sp.) mostrando detalhe da foto anterior. Além do fusionamento das lamelas secundárias e da congestão, pode-se ver um trofonte de Ichthyophthirius multifiliis.

As lesões encontradas são semelhantes às descritas por Paperna (1980), exceto quanto ao aspecto inflamatório que, no caso ora descrito, não mostrou infiltração monocitária significativa.

\section{Abstract}

Ichthyophthirius multifiliis (Protozoa) in acari, Ancistrus sp. (Pisces: Teleostei), captured in Belém, State of Pará

A case of white spot disease in fish Ancistrus sp., named acari, captured in Belém, State of Pará, is reported. The host showed lesions on the surface of the body and branchs. Microscopically, the branchs revealed vascularcongestive process and moderate hemorrhage. There was focal hiperplasy of the secundary lamella, causing fusion of them. The tipic protozoan Ichthyophthirius multifiliis was observed among the lamellar spaces of the branchs.

Key words: Ichthyophthirius multifiliis; ichthyophtiriasis; acari; Ancistrus sp.

\section{Referências bibliográficas}

Eiras JC 1994. Elementos de Ictioparasitologia. Fundação Eng ${ }^{\circ}$ Antonio de Almeida, $339 \mathrm{pp}$.

Hoffman GL 1970. Intercontinental and transcontinental dissemination and transformation of fish parasites with emphasis on whirling disease (Myxosoma cerebralis). Am Fish Soc Spec Publ 5: 69-81.

Paperna I 1980. Parasites, infections and diseases of fish in Africa. CIFA Tech Paper 7, 216 pp.

Reichenbach-Klinke HH 1980. Enfermedades de los Peces, $2^{a}$ ed., Editorial Acribia, Zaragoza, 507 pp.

Roberts RJ 1978. Fish Pathology. Baillière Tindall, London, 318 pp. 